\title{
The impact of internet of things on customer service: A preliminary study
}

\author{
Hebah H. O. Nasereddin ${ }^{1}$, Moath Jehad Mohammad Faqir ${ }^{2}$ \\ ${ }^{1}$ Faculty of Information Technology, Middle East University, Jordan, hnasereddin@ meu.edu.jo \\ ${ }^{2}$ Faculty of Business, Middle East University, Jordan, moath_faqir@ yahoo.com
}

\section{Article Info}

Received Dec 31, 2018.

\section{Keyword:}

Security

Scalability

Satisfaction

Customer Loyalty

Cost

\begin{abstract}
The study discuss about internet of Things on serving passengers at Queen Alia International Airport in Amman, Jordan, by knowing its importance and how to minimize its shortcomings in order to improve customer service at the airport. This research allowed us to understand the fears that travelers had, which, if provided, would ensure greater service improvement. Search results show that there is a great impact on Internet things on customer service. The results showed that the variables (safety and scalability) have a statistically significant impact on customer service. While the cost has a clear positive effect, it is not statistically significant. The study also showed that there is a significant impact on the cost of customer service. Security plays an important role in customer service, meaning that there is a significant security impact on customer service. It shows that the most important factor in customer service is security. Extensibility is the key to a successful Internet object system and it is important to focus on it.
\end{abstract}

\section{Corresponding Author:}

Hebah H. O. Nasereddin

Faculty of Information Technology

Middle East University, Jordan

hnasereddin@meu.edu.jo, hebah66@hotmail.com

\section{Introduction}

The Internet is one of the most important inventions widely used for human service. Its main purpose is to spread knowledge and facilitate communication around the world. Currently the Internet is used in almost everything, whether in search of information or using email or even at the level of any business. Moreover, it is a challenge for many who work without it. Internet of Things (IoT) has emerged in recent years, leading to a new industrial revolution that will eventually change the way we live in our world.

Customer service plays an important role in any cultural, scientific, commercial or other work, as well as improving the company's profit and reputation. Satisfaction can be defined as [1] a person's sense of happiness or frustration resulting from comparing the expected performance, or the outcome of the product with regard to his or her expectations. IoT is a modern technology that enables you to connect things to the Internet, allowing them to communicate with people. [2] Mention that by 2020, billions of items will connect to Internet.

IoT industry began to take place within the world; there is a high competition between different businesses; for example companies always try to get the chance to gain the competitive advantages [3]. IoT improves 
many aspects of one's life; not only saves time but also it's very convenient. Computers can keep track on both the quality and viability of things. Knowing the expiration dates of products surely leads to an improvement in safety and quality [4]. IoT is one of the ways that will cause a reinvention of various industrial sectors leading to a new and more enhanced level of productivity. In addition to that, it will enable machines to conduct work while continually assessing risk. The companies will have the opportunities to identify customers, understand their needs, and facilitate a quick reliable and service.

The IoT revolution sure will save time and effort for everyone. Routine tasks can be easy once you press the button. This enhances customer service as a great service. The aviation sector is highly dependent on the existence of excellent quality standards in the area of customer services. Where customers are a strong supporter of the airline's continued business, the Internet has begun to implement things in the aviation sector to enhance operational efficiency, increase profitability and customer loyalty. The concept behind Internet objects technology is not really very complex. It consists of the latest versions of the Internet, and protocols such as (IPV6), which allows easy identification and location of IP addresses in trillions. [5] One of the most promising technologies is RFID. The concept behind technology works on the basis of electromagnetic fields. Marks help automatically identify and trace objects associated with them. In our case, baggage and cargo handling are considered to be objects. RFID is sure to save time and effort and increase the quality of luggage handling during trips. The application of these technologies will radically change business models. This makes the check-in process for large numbers of passengers an easy task. It avoids slow processing of passenger information. [6] Quality control is necessary as part of a network of interconnected data, the Internet provides the opportunity to perform a full audit and identify certain trends such as potential malfunction or damage.

\section{Theoretical Framework}

This section includes many aspects that have been observed through previous studies related to IoT and customer service. Previous studies have been reviewed to determine how the other researchers discuss about IoT. IoT according to [10], used as a cover several sides related to the expansion of the Internet, through the wide distributed devices. IoT imagines a future, in which digital objects could be connected, through communication technologies, which enable an entire new level of services and applications. While [11] discussed the challenges that will face the IoT, showed that analysis is centered on mobility, reliable control and actuation, and finally scalability which is the most important in IoT deployments [12], [13] Discover the innovative of the IoT with focus on the role of communication protocols, which enable communication between node and hub in the IoT design. IoT as [14] discuss is an emerging matter of economic importance, technical and social, Consumer products, industrial components and many other items are being joined with Internet connectivity and data analytic abilities that will lead to convert the living way[15]. In the future IoT will affect the world econom, and around billions devices will be work through IoT, in addition the global economy impact of more than 11 trillion dollar[16]. The term IoT is also named as the Internet of Everything $[17,18]$. [19] Discussed the impact of social media marketing on customer satisfaction over brand image. Over the past years many study models have been focused on study of expected customer Service through the use of technology, in addition to the factors of confidence and safety were prepared as the most important factors to determine customers' intent to integrate into E-marketing.

\section{Problem Statement}

IoT industry began expand to take a place within the business and government. During the high competition between companies, they try to get the chance to gain the competitive advantages. IoT aims to improve the performance and quality of work and to facilitate businesses. IOT have many advantages such as saving time, decreasing total costs, improving communication; increase the efficiency of automation and control which lead to Customer Service. As a researchers know IoT technologies at airports appeared lately in many countrys such as UK, USA, Dubai, Qatar and Jordan. Figure 2 show some IoT photos at Queen Alia International Airport in Amman. So the core problem of this study is:

"Is there any Impact of Internet of Things on Customer Service in Queen Alia International Airport"? 
This study tests four hypotheses according to the Problem Statement, which show as following:

- There is no direct impact of IoT (security, cost, and scalability) on Customer Service, at the level of significance $(\alpha \leq 0.05)$.

- There is no direct impact of IoT security on Customer Service at the level of significance $(\alpha \leq 0.05)$.

- There is no direct any impact of IoT Cost on Customer Service, at the level of significance $(\alpha \leq 0.05)$.

- There is no direct impact of IoT scalability on Customer Service, at the level of significance ( $\alpha \leq$ $0.05)$.

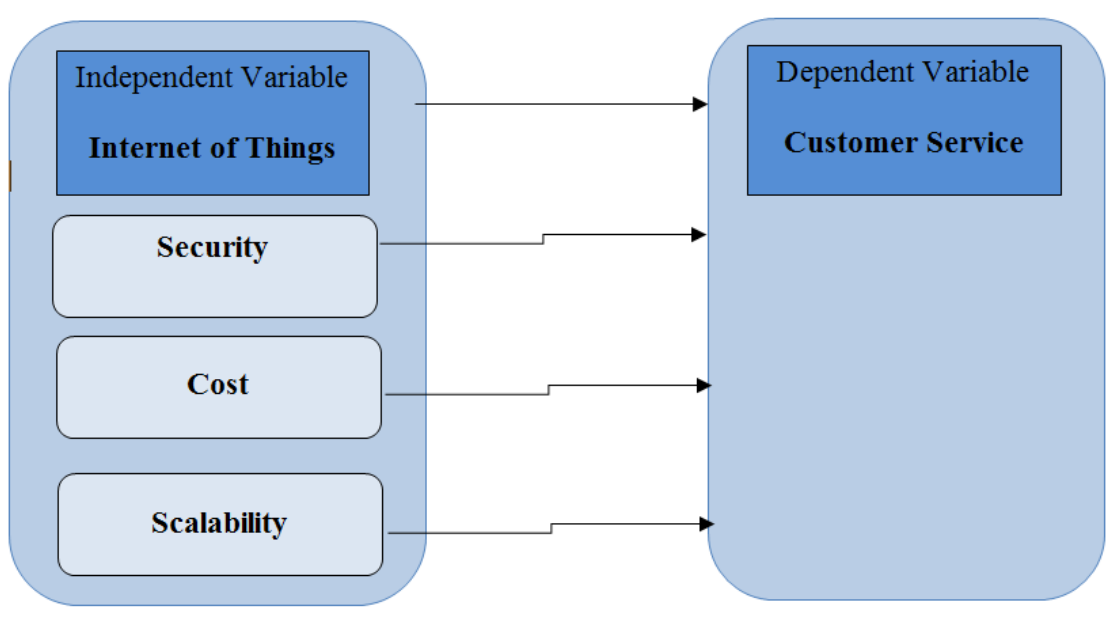

Figure (1): Study model.
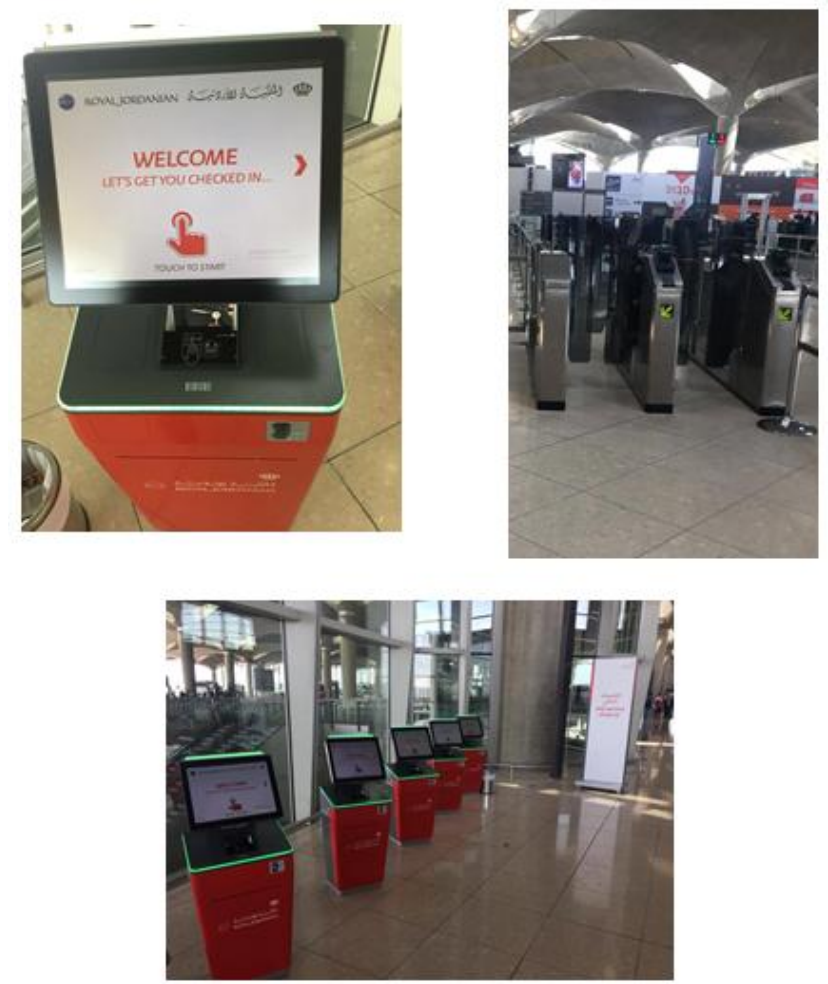

Figure 2: IoT photos at Queen Alia International Airport in Jordan 


\subsection{Methodology}

This section describes the methodology used in this study, describe the study data collection tools, reliability, validity, and then explain the study variables and statistical tools. This study follows the descriptive and analytical approach. Data collected to investigate the impact of IoT on Customer Service on Queen Alia international Airport, which is the main and largest airport in Jordan. In order to determine the size of the study population and sample the researchers obtained the historical data on the number of passengers through Queen Alia International Airport in 2018, which were 8.6 million passengers. Study is based on a stratified random proportional sample for passengers in Queen Alia International Airport in Amman. The sample study size was 450 passengers.

\subsection{Result}

Factor analysis was used to determine the variance. The results had factor loadings ranged from 0.55 to 0.90 . The results also indicated that Cronbach Alpha ranged from 0.7196 to .8180 , indicating reliability of the items measuring exceeding the threshold limit of 0.60. Table 2 shows the Reliability, Mean and Standard Deviation.

Table 2: Factor loading Reliability, Mean and Standard Deviation

\begin{tabular}{|c|c|c|c|}
\hline Constructs/Items & Cost & Scalability & Security \\
\hline $\begin{array}{c}\text { Total Alpha } \\
\text { Cronpach } \\
.8886 \\
\text { Alpha Cronpach }\end{array}$ & .7196 & .8183 & .7856 \\
\hline Mean & 3.62 & 3.89 & 3.80 \\
\hline Standard Deviation & .74 & .63 & .58 \\
\hline $\begin{array}{l}\text { Cost } 1 \\
\text { Cost } 2 \\
\text { Cost } 3 \\
\end{array}$ & $\begin{array}{l}.777 \\
.691 \\
.578 \\
\end{array}$ & & \\
\hline $\begin{array}{l}\text { Scalability } 1 \\
\text { Scalability } 2 \\
\text { Scalability3 }\end{array}$ & & $\begin{array}{r}.559 \\
.831 \\
.630 \\
\end{array}$ & \\
\hline $\begin{array}{l}\text { Security } 1 \\
\text { Security } 2 \\
\text { Security } 3 \\
\text { Security } 4 \\
\text { Security } 5 \\
\end{array}$ & & & $\begin{array}{l}.797 \\
.553 \\
.759 \\
.703 \\
.597\end{array}$ \\
\hline
\end{tabular}

Tables (3 -10) below, summarizes the simple linear regression for hypotheses. The tables show the standardized regression coefficient of $\mathrm{R}$ and $\mathrm{R}^{2}$, for all the predictors in linear regression analysis.

- Hypothesis: There is no direct impact of IoT security on Customer Service at the level of significance $(\alpha \leq 0.05)$.

Table 3, 4, shows that the entire model has a significant effect on Customer Service $(p<0.05) . \quad R^{2}$ In the entire model of the IoT security explains $.198 \%$ of the variance. 
Table 3 (Model Summary)

\begin{tabular}{|l|l|l|l|l|}
\hline Model & R & R Square & $\begin{array}{l}\text { Adjusted } \\
\text { R Square }\end{array}$ & $\begin{array}{l}\text { Std. Error of } \\
\text { the Estimate }\end{array}$ \\
\hline 1 & $.445(\mathrm{a})$ & .198 & .191 & .202 \\
\hline
\end{tabular}

a Predictors: (Constant), security

Table 4 (Coefficients (a))

\begin{tabular}{|c|c|c|c|c|c|}
\hline \multirow[t]{2}{*}{ Model } & \multicolumn{2}{|c|}{ Unstandardized Coefficients } & \multirow{2}{*}{$\begin{array}{l}\text { Standardized } \\
\text { Coefficients } \\
\text { Beta }\end{array}$} & \multirow[b]{2}{*}{$\mathrm{t}$} & \multirow{2}{*}{ Sig. } \\
\hline & $\mathrm{B}$ & Std. Error & & & \\
\hline $\begin{array}{l}1 \\
\text { (Constant) } \\
\text { security }\end{array}$ & $\begin{array}{l}1.539 \\
-.134\end{array}$ & $\begin{array}{l}.094 \\
.026\end{array}$ & -.445 & $\begin{array}{l}16.313 \\
-5.262\end{array}$ & $\begin{array}{l}.000 \\
.000\end{array}$ \\
\hline
\end{tabular}

a Dependent Variable: Accept

- Hypothesis: There is no direct any impact of IoT Cost on Customer Service, at the level of significance $(\alpha \leq 0.05)$.

Table 5 and table 6 shows that the entire model has no significant effect on Customer Service $(p=.225>0.05) . R^{2}$ In the entire model of the IoT Cost explains $.002 \%$ of the variance

Table 5 (Model Summary)

\begin{tabular}{|l|c|r|r|r|}
\hline Model & R & R Square & $\begin{array}{r}\text { Adjusted } \\
\text { R Square }\end{array}$ & $\begin{array}{r}\text { Std. Error of } \\
\text { the Estimate }\end{array}$ \\
\hline 1 & $.040(\mathrm{a})$ & .002 & -.007 & .225 \\
\hline
\end{tabular}

a Predictors: (Constant), Cost

Table 6 (Coefficients (a))

\begin{tabular}{|l|r|r|r|r|r|}
\hline \multirow{2}{*}{ Model } & \multicolumn{2}{|c|}{$\begin{array}{c}\text { Unstandardized } \\
\text { Coefficients }\end{array}$} & \multicolumn{1}{c|}{$\begin{array}{c}\text { Standardized } \\
\text { Coefficients }\end{array}$} & \multicolumn{1}{c|}{$\mathrm{t}$} & \multirow{2}{*}{ Sig. } \\
\cline { 2 - 6 } & \multicolumn{1}{|c|}{$\mathrm{B}$} & \multicolumn{1}{c|}{$\begin{array}{c}\text { Std. } \\
\text { Error }\end{array}$} & \multicolumn{1}{c|}{ Beta } & & \\
\hline 1 & .997 & .133 & & 7.494 & .000 \\
(Constant) & $1.419 \mathrm{E}-02$ & .034 & .040 & .421 & .675 \\
\hline
\end{tabular}

a Dependent Variable: Accept

- Hypothesis: There is no direct impact of IoT scalability on Customer Service, at the level of significance $(\alpha \leq \mathbf{0 . 0 5})$.

Table 7 and 8, shows that there is a significant effect on Customer Service $(p<0.05) . R^{2}$ In the entire model of the scalability explains. 
Table7 (Model Summary)

\begin{tabular}{|c|c|c|c|c|}
\hline Model & $\mathrm{R}$ & R Square & $\begin{array}{c}\text { Adjusted } \\
\text { R Square }\end{array}$ & $\begin{array}{c}\text { Std. Error of } \\
\text { the Estimate }\end{array}$ \\
\hline 1 & $.223(\mathrm{a})$ & .050 & .041 & .220 \\
\hline
\end{tabular}

Table 8 (Coefficients (a))

\begin{tabular}{|c|c|c|c|c|c|c|}
\hline \multirow{2}{*}{\multicolumn{2}{|c|}{ Model }} & \multicolumn{2}{|c|}{$\begin{array}{l}\text { Unstandardized } \\
\text { Coefficients }\end{array}$} & $\begin{array}{l}\text { Standardized } \\
\text { Coefficients }\end{array}$ & \multirow[b]{2}{*}{$\mathrm{t}$} & \multirow[b]{2}{*}{ Sig. } \\
\hline & & $\mathrm{B}$ & Std. Error & Beta & & \\
\hline \multirow[t]{2}{*}{1} & (Constant) & 1.450 & .165 & & 8.775 & .000 \\
\hline & USEFULNE & -.099 & .041 & -.223 & -2.425 & .017 \\
\hline
\end{tabular}

a Dependent Variable: Accept

- Hypothesis: There is no direct impact of IoT (security, cost, and scalability) on Customer Service, at the level of significance $(\alpha \leq 0.05)$.

A multiple regression model was used. Results indicated that out of the three hypotheses that were tested for significance, two were found to be highly significant, COST (standardized $b=-.154, p<.05$ ) and scalability $(b=7.274 \mathrm{E}-02, \mathrm{p}<.05)$ were found to be impact on Customer Service. However, the regression results and the total variance explained by the model are presented in Tables 9 and 10.

Table 9 Model Summary

\begin{tabular}{|l|l|r|r|r|}
\hline Model & R & R Square & $\begin{array}{c}\text { Adjusted } \\
\text { R Square }\end{array}$ & $\begin{array}{c}\text { Std. Error of } \\
\text { the Estimate }\end{array}$ \\
\hline 1 & $.535(\mathrm{a})$ & .286 & .231 & .198 \\
\hline
\end{tabular}

a Predictors: (Constant), cost, scalability, security

Table 10 Coefficients (a)

\begin{tabular}{|l|r|r|r|r|r|}
\hline \multirow{2}{*}{ Model } & \multicolumn{2}{|c|}{$\begin{array}{c}\text { Unstandardized } \\
\text { Coefficients }\end{array}$} & $\begin{array}{l}\text { Standardized } \\
\text { Coefficients }\end{array}$ & \multicolumn{2}{|c|}{} \\
\cline { 2 - 6 } & \multicolumn{1}{|c|}{$\mathrm{B}$} & \multicolumn{1}{c|}{$\begin{array}{c}\text { Std. } \\
\text { Error }\end{array}$} & \multicolumn{1}{c|}{ Beta } & \multicolumn{1}{c|}{$\mathrm{t}$} & \multicolumn{1}{c|}{ Sig. } \\
\hline 1 (Constant) & 1.382 & .195 & & 7.081 & .000 \\
COST & -.154 & .037 & -.506 & -4.204 & .000 \\
scalability & $7.274 \mathrm{E}-02$ & .039 & .204 & 2.844 & .048 \\
SECURITY & $1.197 \mathrm{E}-02$ & .048 & .031 & .249 & .804 \\
& & & & & \\
\hline
\end{tabular}

a Dependent Variable: Accept

\section{Conclusion}

The research identify the Impact of Internet of Things on Customer Service in Queen Alia International Airport in Jordan by identifying factors, advantages, disadvantages, and how to reduce the obstacles in order to have Customer Service. The research allowed us to figure out the fears and concerns these consumers had towards these factors which, if furnished to the service provider, would ensure an increased possibility of a successful implementation of the service. The results of the research proved that there is impact of IoT on Customer Service. The result show that the variables (Security, Scalability), that significance, indicating that Security, Scalability have a statistically significant effect on Customer Service, and the (Cost) has a positive effect that is apparent, but not statistically significant. There is impact of Cost at the significant level on Customer Service. The security plays a significant role in Customer Service that showed that the most 
dominant factor on airport Customer Service was the security. The scalability is the main key for a successful IoT system and it's important to focus in it.

\section{Acknowledgements}

The authors are grateful to Middle East University, Amman, Jordan for the financial support granted to cover the participation in the conference and the publication fee of this research article.

\section{References}

[1] Singh, H. (2006). The importance of customer satisfaction in relation to customer loyalty and retention. Academy of Marketing Science, 60, 193-225.

[2] Guerra, D. (2012). The internet of things: developing a sustainable competitive advantage in the Hotel Industry (Doctoral dissertation).

[3] Nasereddin, Hebah H.O." Internet penetration and the constraints on the Use of E-commerce". The Journal of Information Technology, Volume 2(2011).

[4] Nasereddin Hebah H. O \& Abdelkarim.A."SMARTPHONE CONTROL ROBOTS THROUGH BLUETOOTH", International Journal of Research and Reviews in Applied Sciences, pp 399- 404 (2010).

[5] "Business Continuity Based on RFID" published in the American Academic \& Scholarly Research Journal by Waleed K. A. Abdulrahema Hebah H. O. Nasereddin, Said M. H. Fares Vol. 5, No. 3, April 2013, .pp 223- 228

[6] Nasereddin, Hebah H.O \& Abdelkarim, Amjad. A, "Mobile commerce". International Journal of Academic Research: Mathematics and Technology, Number 4(1), October 2010.pp 148-154

[7] Gulliksson, P., \& Riis, J. (2017). A case study of IoT companies active in the Swedish market; online marketingstrategies and online communication.

[8] Roman, R., Zhou, J., \& Lopez, J. (2013). On the features and challenges of security and privacy in distributed internet of things. Computer Networks, 57(10), 2266-2279.

[9] Ganiyu, R. A., Uche, I. I., \& Adeoti, O. E. (2012). Is customer satisfaction an indicator of customer loyalty?. Australian Journal of Business and Management Research, 2(7), 14.

[10] Miorandi, D., Sicari, S., De Pellegrini, F., \& Chlamtac, I. (2012). Internet of things: Vision, applications and research challenges. Ad hoc networks, 10(7), 1497-1516.

[11] Yannuzzi, M., Milito, R., Serral-Gracià, R., Montero, D., \& Nemirovsky, M. (2014, December). Key ingredients in an IoT recipe: Fog Computing, Cloud computing, and more Fog Computing. In Computer Aided Modeling and Design of Communication Links and Networks (CAMAD), 2014 IEEE 19th International Workshop on (pp. 325-329). IEEE.

[12] ALanoud Ibrahim Alhrout, Hebah H.O.Nasereddin, FROM THE FANTASY WORLD TO REALITY: SMART CITIES International Journal of Research and Reviews in Applied Sciences. Volume IJRRAS 35 (2) • May 2018 .pp 42- 46.

[13] Bruse, E. (2015). Internet of Things: Definition, applications and comparison of wifi-based communication protocols for implementation of an irrigation system.

[14] Rose, K., Eldridge, S., \& Chapin, L. (2015). The internet of things: An overview. The Internet Society (ISOC), 1-50.

[15] Lee, I \& Lee, K. (2015). The Internet of Things (IoT): Applications, investments, and challenges for enterprises. Business Horizons, 58(4), 431-440.

[16] Hefnawy, A., Bouras, A., \& Cherifi, C. (2016, March). Iot for smart city services: Lifecycle approach. In Proceedings of the International Conference on Internet of things and Cloud Computing (p. 55). ACM.

[17] Bogicevic, V., Bujisic, M., Bilgihan, A., Yang, W., \& Cobanoglu, C. (2017). The impact of traveler-focused airport technology on traveler satisfaction. Technological Forecasting and Social Change, 123, 351-361.

[18] Nasereddin, Hebah H. O \& Khazneh, Shireen Y.M," AN EMPIRICAL STUDY OF FACTORS AFFECTING THE ACCEPTANCE OF MOBILE PAYMENTS IN JORDAN", International Journal of Research and Reviews in Applied Sciences, Volume IJRRAS 29 (3) • December 2016 .pp 110121 
[19] Moh'd, A. (2017). The Impact of Social Media Marketing on Customer Satisfaction through Brand Image (Field Study based on Customers of Jordan Telecommunication Companies, Applied on the Students of the Private Universities that Located in Amman-Jordan), (Unpublished master thesis), Middle East University, Amman, Jordan.

[20] Nasereddin, Hebah H.O, "MMLSL: Modelling Mobile Learning for Sign Language". Of Engineering and Computer Science Research and Reviews in Applied Sciences, Volume Volume 9 issue (2) 2017 .pp 20267-20272

\section{Bibliography Authors}

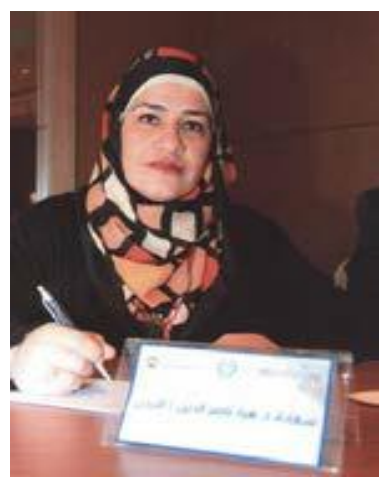

Hebah H. O. Nasereddin, Professor in Faculty of Information Technology, Middle East University (MEU), Amman, Jordan. Nasereddin is a reviewer for several National and International journals and a keynote speaker for many conferences, general chair for ICNVICT. She is supervising many MSc, and Diploma thesis. Her research is focused on Data warehouse, Data Mining, Cryptography, Steganography, and Big Data. Prof Nasereddin published in Computer Philosophy and other Computer topics publications. She is Chief Editor and Editor for several Magazines in addition to her participation in project research evaluations.

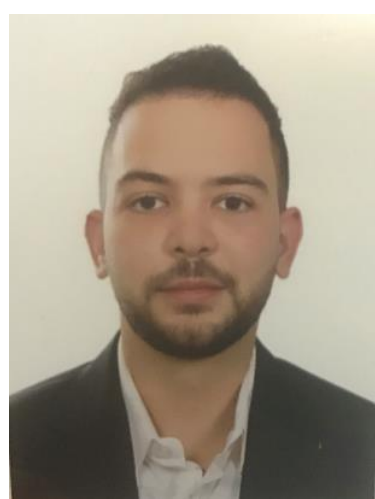

MOATH JEHAD MOHAMMAD FAQIR graduated from Arab Academy for Science, Technology and Maritime Transport" (Egypt) in 2015. Ever since his graduation, he participated in many training courses in Jordan such as (NASP) Safety and Health for Safety Engineers course (The American University in Cairo), IOSH Managing Safety; Institutional of Occupational Safety and Health (IOSH) (Jordan), NEBOSH -Health \& Safety at work (Jordan Engineering Association). FAQIR became a certified Auditor after completing the following courses: ISO 14001 EMS lead Auditor Training course, OHSAS 18001 SMS lead Auditor Training course, ISO 9001 QMS lead Auditor Training course, ICOSH (International Certificate in Occupational Safety \& Health). Practically, he had good experience ever since he graduated by working for Jordan Electricity Company as Safety Engineer. Moath completed Master's degree in E-Business / Middle East University of Jordan with Grade (GPA): (Excellent) with Honor Degree in 2019 which ranked him the first in his graduation year. 